\title{
Toward a Transdisciplinary Rural Education Research Agenda
}

\author{
Christopher J. Stapel \\ University of Kentucky
}

\author{
Alan J. DeYoung, \\ University of Kentucky
}

This paper examines the representation of rural education research orientations - defined in terms of methodological approach, academic focus and place-consciousness - within the literature and across academic disciplines. A content analysis of 155 abstracts from articles published in the Journal of Research in Rural Education and Rural Sociology between 1997 and 2008 reveals that most rural education research is not quantitative, not academically-oriented and not placeconscious. Furthermore, the abstracts show that Rural Educators are underrepresented in academically-oriented research while Rural Social Scientists are overrepresented in that dimension. The implications of these findings for collaboration are discussed and a policy-relevant, innovative, transdisciplinary research agenda is outlined.

Key words: Rural sociology; education research; research methods; transdisciplinary; content analysis.

The rural school has served as a laboratory for scholars across academic disciplines for over a century (DeYoung, 1987; Theobald, 1991). The inaugural issue of the oldest American education journal, Journal of Education, examined formal agriculture education practices (Farmer, 1838), and the first issue of the Rural Sociological Society's flagship journal, Rural Sociology, included studies of the health of school children and the attitudes of high school seniors toward farming (Holt, 1936). More recently, several orientations toward rural education research, differentiated in terms of methodological approach, attentiveness to academic outcomes and degree of place-consciousness, have emerged. The purpose of this study is to determine the extent to which these research orientations are represented within the literature and across disciplines, and to offer strategies for developing stronger transdisciplinary rural education research collaborations that we argue are necessary in the contemporary education policy climate.

Those who conduct rural education research can be placed in at least two disciplinary categories. The first category, Rural Educators, is comprised of individuals with appointments in colleges of education, while the second category, Rural Social Scientists, includes scholars from outside colleges of education. The latter category is largely made up of individuals from colleges of agriculture and liberal arts. Additionally, a significant number of Rural Social Scientists work for regional education laboratories, government agencies and nonprofit institutions. Of course, the labels we assign to these organizational and departmental categories should not suggest that the work of these two groups is mutually exclusive; certainly many Rural Educators conduct social science research and many Rural Social Scientists engage with teaching, learning and educational outcomes.

While the histories of the Rural Education and Rural Social Science communities are robust, at present the two groups potentially maintain distinct research orientations. We posit that disciplinary expectations, institutional contexts and public policy landscapes encourage researchers from a given disciplinary affiliation to conduct research of a specific orientation. More precisely, we hypothesize that Rural Educators are compelled to engage in spatially decontextualized studies of academic outcomes of students who only happen to be situated within rural places. On the other hand, we expect that Rural Social Scientists are encouraged to study the social and spatial contexts of rural schooling and thus conduct research that is particularly sensitive to place.

In the following pages we first outline the disciplinary contexts of the Rural Education and Rural Social Science research communities. Second, we highlight previous reviews of rural education scholarship and place our study among a literature calling for transdisciplinary rural and education research. Third, we describe the data and analytical approach used in our content analysis of 155 rural education journal article abstracts published between 1997 and 2008. We conclude by discussing strategies that Rural Educators and Rural Social Scientists might pursue in order to engage in more efficacious transdisciplinary research.

\section{Context}

\section{Disciplinary Influences}


The work of Rural Educators and Rural Social Scientists is informed by markedly different institutional contexts and by contemporary public policies. Standardsbased federal, state and local policies, and the funding attached to them, place a high value on research that measures and helps improve upon academic outcomes of individual students. Federal law mandates that education policies be grounded in "scientifically based research," preferably derived from national datasets (United States Department of Education [USDOE], 2001). The largest and most recent federal education funding package, Race to the Top, requires states to adopt (quantitative) data systems tied to student performance (USDOE, 2009). Arguably, then, education scholars must engage in highly empirical, outcomes-oriented research in order to remain policy-relevant.

Perhaps the corollary disciplinary, professional and institutional incentives for Rural Educators to engage in experimental analyses of academic interventions - rather than in interpretive studies of social and spatial contexts of schooling - explain the observation that many rural education manuscripts fail to describe "the rural context of research" (Coladarci, 2007, p. 2). Indeed a problem persists "that rural education researchers, in their reports and publications, typically fail to describe the context of their research in sufficient detail" (Coladarci, 2007, p. 2). Furthermore, contemporary education policies endorse centralized, bureaucratic accountability measures that largely ignore the structural peculiarities of rural schools and communities. The decontextualization of policy formation and implementation results in a decontextualization of (rural) education research. Hence much of the rural education research fails to make a rural case because first, "far too often, it remains unclear whether the researcher has discovered a rural phenomenon or, instead, a phenomenon that is observed incidentally in a rural setting" (Coladarci, 2007, p. 3), and second, claims of inherently rural best practices fail to be rigorously scrutinized.

A different set of influences is derived from the disciplinary, professional and institutional positions of Rural Social Scientists. Historically, Rural Social Science research in the United States - in particular, sociological research - has been situated in land-grant colleges and universities (Beaulieu, 2005). The mission of these institutions was, and still is in part, to disseminate academic knowledge to practitioners and laypeople throughout a state; successful completion of this task requires sensitivity to local practices. As such, one expects place-consciousness to be a hallmark of Rural Social Science.

Significant funding from the United States Department of Agriculture (USDA) administered by statebased agricultural experiment stations (Krannich, 2008) has supported this work over time. Given the de facto (albeit arguably insignificant at present) fiscal relationship between land-grant institutions and the USDA, "reliance on such funding has constrained the focus and scope of much rural sociological research to topics that fit within whatever may be included in the then-current USDA agenda of priorities and to issues and locations deemed relevant by Experiment Station administrators whose interests most often are centered within their own state" (Krannich, 2008, p. 6). Admittedly, a majority of these localized topics are agriculture-, food- and natural resources-related. However funding is available for integrated Rural Social Science research from the USDA Agriculture and Food Research Initiative (AFRI) for projects incorporating a place-based outreach or educational component (USDA, 2009).

\section{A Call for Collaboration}

Rural Educators and Rural Social Scientists who conduct education research undoubtedly share a common commitment to local schools and rural communities. For example, "one portion of the literature on rural education explicitly or implicitly espouses the view that a strong connection to the community and sense of place are values to be preserved in rural areas. It suggests that what is at risk is not the individual students, but rather, the community as a whole. Thus, a large part of the literature on rural education is based upon the belief that rural areas should be preserved, and that keeping rural communities intact must be a goal of education" (Khattri, Riley \& Kane, 1997, p. 81).

A tension exists, though, between Rural Educators and Rural Social Scientists who wish to simultaneously inform policy, remain sensitive to the complexities of rural communities and adhere to institutional and disciplinary expectations; encouragingly, a shared desire to work collaboratively exists as well. Prominent voices in the Rural Education and Rural Social Science research communities have advocated for greater transdisciplinary collaboration. The need for collaboration among those who study rural education is particularly acute given that there exists "relatively little networking in the professional and research communities around rural education research" (Sherwood, 2000, p. 160).

In his departing editorial in the Journal of Research in Rural Education (JRRE), Coladarci (2007) observed "rural education research often is conceived rather narrowly, not taking advantage of disciplines outside mainstream education. By drawing deeply from such disciplines as sociology (e.g., see Beaulieu, 2005), history, anthropology, and psychology for framing their questions and conducting their investigations, rural education researchers collectively will make greater gains 
in understanding and improving education in rural communities" (p. 6). He urged rural education scholars to incorporate the rural context more thoroughly into their work and stressed that "rural education research would be better off if investigators looked more broadly and drew more deeply with respect to other disciplines that can inform their work" (p. 6). The community of Rural Sociologists, and Rural Social Scientists more broadly, may be particularly well-placed as partners in this rural education research endeavor. For example, rural Social Scientists have recently made calls for transdisciplinary collaboration, the most urgent of them voiced by rural sociologists. The vitality of rural sociology as an academic discipline has dropped precipitously in recent years as evidenced by decreases in the number of rural sociology faculty, graduate students and Rural Sociological Society (RSS) members, and by the virtual disappearance of stand-alone departments of rural sociology (Beaulieu, 2005; Krannich, 2008). In response to this decline, many rural sociologists have yielded to institutional pressures to work across disciplines, hence the emergence of journals of rural and community studies and hybrid social science departments in land-grant colleges of agriculture. Former RSS president Bo Beaulieu (2005) challenged members of the society to move "beyond discipline-based research" (p. 8) and build partnerships with colleagues within the discipline, outside of the discipline and with those in policy and practitioner roles as a strategy for sustaining the organization. In doing so, he invoked the historical commitment of rural sociologists to the public (e.g. Sanders, 1958) and the recent call for a "public sociology" that has emerged from the American Sociological Society (e.g. Burawoy, 2004).

With these disciplinary contexts in mind it seems that Rural Educators and Rural Social Scientists (or at least a subgroup of rural sociologists) face a timely and wellsuited opportunity for collaboration as each has much to offer the other. For example, the socio-spatial theoretical orientation of Rural Social Scientists has the potential to contextualize the empirical work of Rural Educators studying rural communities. Likewise, the methodological and policy expertise of Rural Educators may guide Rural Social Scientists to questions relevant to local classrooms, schools and districts. The potential in transdisciplinary collaboration is enormous given the shared belief that as a group, we are committed to social change that will promote the well-being of rural people and communities. That commitment is reflected in a strong focus on addressing real-world problems through original research, information dissemination, policy assessment, and action. We are highly inclusive and value the ways in which a variety of disciplinary perspectives, theoretical orientation, and methodological approaches can illuminate the conditions and changes confronting rural societies around the globe. (Krannich, 2008, p. 14)

Yet the entropy that stands in the way of collaborative discourse is oftentimes of even greater magnitude. Rural sociology, for example, "appears to have made only limited progress in adapting to changing circumstances that affect both the institutional contexts in which most of us are employed and the rural people, communities, and societies that are the focal points of our work" (Krannich, 2008, p. 2).

\section{Relevant Literature}

Published reviews, critiques and content analyses of rural education scholarship are not uncommon, but no one has specifically investigated disciplinary variations in research orientation. In an early review, DeYoung (1987) acknowledged - but failed to account for - disciplinary variation in rural education scholarship. He claimed that "research on the particular problems and issues in rural education is relatively obscure, lacking in focus, and comparatively unsophisticated" (p. 136), that "much of the scholarship on rural education in this country is relatively unsophisticated compared with most research found in mainstream educational research journals" ( $p$. 141) and that historically "the best scholarship in this area was carried out by anthropologists and historians rather than by educational researchers more indebted to psychological or sociological foundation" (p. 141). The rural education research priorities at the time included the utilization of large-scale datasets, the creation of an unambiguous definition of rurality and a strengthening of relationships between schools and communities (DeYoung, 1987).

In a subsequent review, Kannapel and DeYoung (1999) summarized seminal works in rural education from decades (1980s and 1990s) when "education reform" was on the national agenda. They found very little in the way of rural school reforms that focused specifically on the local: "the rural school problem today is that generic, standardized modes of reform continue to predominate in education policymaking" (p. 72). They argued that policies privileging centralized schooling over placebased models of control had given rise to detrimental rural education practices that neglected community in the name of efficiency. In advocating for reforms that "build on rural schools' existing strengths, particularly their strong ties to local communities" (p. 76) Kannapel and DeYoung advanced an approach that privileges the social context of a particular place rather than its position relative to other locales.

In an evaluation of rural education research quality, Arnold, Newman, Gaddy and Dean (2005) found that 
studies "employing a 'comparative' (broadly defined) research design to investigate a rural education problem" (p. 1) were grossly underrepresented in the literature. In addition to identifying the most popular rural education topics between 1991 and 2003, the research team evaluated the (scientific) quality of journal articles and found that none met the No Child Left Behind Act, (NCLB, 2001) gold standard of an experimental, randomized design. Fewer than half the studies were comparative and only $10 \%$ were quasi-experimental and therefore able to draw causal inferences. Their findings suggested that rural education research is weakly positioned to evaluate "the causes of different student outcomes and the efficacy of interventions" (Arnold et al., 2005 , p. 9) since most rural education journal articles fall short of the NCLB scientifically based research requirement.

Other rural education researchers took issue with the methodological scope of Arnold et al. (2005), most notably Howley, Theobald, and Howley (2005) who replied that "consideration of rural meaningfulness is essential to rural education research" (p. 2). They argued that place-conscious research attentive to the everyday lifeworlds of rural people can be conducted via "historical, ethnographic, and other forms of research that rely more on analysis of language" (p. 1) in addition to the more empirical methods privileged by Arnold and colleagues. Such methods, though,

inevitably draw on sociology, and as a result, they are at the moment out of favor with a regime that believes that intellectual accomplishment is represented in test scores, finds that teaching is an educational intervention, and generally takes context as an impediment to learning rather than as a motive for learning and source of meaning. (Howley et al., p. 4)

Arnold (2005) responded to these criticisms by labeling Howley et al. (2005) as Rural Conservatives (Rural-Cons) who engage in "advocacy research", in contrast to place-conscious Progressive Rurals (ProRurals), like himself, who remain neutral in light of contradictory evidence. Arnold's colleagues, Cicchinelli and Dean (2005), responded

it is no longer adequate, in this day and age of research sophistication, to argue the value and success of rural education based solely on belief in and passion for rural communities. Nor is it adequate to argue that rural education is too unique to be the subject of rigorous research, or that scientific inquiry and sound decision-making are not relevant to rural education and communities. (p. 2)

Most recently, Coladarci (2007) expressed concern that the absence of a current and comprehensive synthesis of research in rural education is an impediment to researchers (particularly newcomers to rural education research), and it also hinders the work of practitioners, policymakers, and others who wish to use the findings of research to inform their craft. (p. 6)

and called for "a sequel" to DeYoung's (1987) review of the literature. This project represents an initial step toward completing that task. It seems critical, though, to first query the degree of divergence (or convergence) between Rural Educators and Rural Social Scientists given the collaborative potential found in their shared commitment to rural schools and communities alongside the confusion and discord described above. With Coladarci's call in mind we aimed to answer the following questions:

1. To what extent are the research orientations employed by rural education scholars - defined in terms of method, academic focus and placeconsciousness - represented within the literature?

2. To what extent do the research orientations vary with respect to the disciplinary affiliations of researchers?

\section{Method}

\section{Data}

The data for our project were abstracts of rural education journal articles published in the Journal of Research in Rural Education (JRRE) and Rural Sociology $(R S)$ between 1997 (the year of the most recent source reviewed by Kannapel and DeYoung) and 2008. JRRE was identified as a primary peer-reviewed publication for Rural Educators; $R S$ was included because of its impact relative to other peer-reviewed Rural Social Science journals. Abstracts were used as proxies for full manuscripts in order to isolate the primary themes in the literature. Thirty-two book reviews, commentaries, editorials, correspondences and articles without abstracts were excluded from analysis. All remaining article abstracts from JRRE were included; remaining abstracts from $R S$ were restricted to those from articles generated from a database search on the following terms: EDUCAT* OR SCHOOL* OR STUDENT* OR ACADEMIC* OR TEACH* OR LEARN* OR INSTRUCT* ${ }^{*}$. In total we analyzed 155 abstracts: 137 from articles published in Journal of Research in Rural Education and 18 from Rural Sociology.

Variables. We conceptualized research orientation along three dimensions that emerged from Coladarci (2007) and the dialogue between Arnold and Howley and their colleagues: methodological approach, academic focus and place-consciousness. Next, we operationalized each dimension as a categorical variable. The 155 
abstracts were read, analyzed and coded such that every article was scored with respect to all three variables. The first variable was a quantitative measure that indicated whether or not the primary analytical technique of an article was quantitative. Articles relying primarily on a quantitative technique - whether descriptive, predictive or causal - were coded yes while all others whether qualitative, theoretical or policy analytical - were coded no. The second variable was an academic outcome measure that indicated whether or not an article defined an academic outcome - such as standardized test score, grade point average or educational attainment - as the primary dependent variable. The third dimension was a place-conscious variable that indicated whether or not an article accounted for the influence of place upon the primary unit of analysis. Every article was coded either yes or no on the academic outcome and place-conscious variables. When these variables were indiscernible from the abstract and in cases where we disagreed on coding we referred the body of the manuscript for confirmation.

\section{Findings}

\section{Research Orientations}

Our first task was to determine the representation of research orientations within the literature. Of the 155 articles, $59(38.1 \%)$ relied primarily on quantitative analytical techniques, 25 (16.1\%) defined an academic measure as the primary dependent variable and 48 $(31.0 \%)$ accounted for the influence of place upon the primary unit of analysis.

Table 1 is a $2 \times 2 \times 2$ matrix representing the eight possible intersectional research orientations. The plurality $(35.5 \%)$ of articles was neither quantitative, academically-focused nor place-conscious. About one quarter $(25.5 \%)$ of the publications comprised nonquantitative accounts of the influences of place on nonacademic outcomes. Slightly fewer articles (21.3\%) were quantitative analyses that did not incorporate academic outcomes or account for influences of place. Perhaps the most striking finding reflected in this initial display is what research orientations are not employed. Just 7 $(11.9 \%)$ of the 59 quantitative papers adequately accounted for spatial influences on the unit of analysis and only $2(2.1 \%)$ of the 96 non-quantitative papers investigated academic outcomes. It appears that research orientations of rural education researchers are segregated along methodological lines: quantitative researchers privileged questions irrespective of place while those producing qualitative/theoretical scholarship tended not to focus on academic outcomes.

Table 1

Frequencies of Research Orientations

\begin{tabular}{|c|c|c|c|c|c|}
\hline & & \multicolumn{2}{|c|}{$\begin{array}{c}\text { Quantitative: Yes } \\
\text { Academic Outcome }\end{array}$} & \multicolumn{2}{|c|}{$\begin{array}{c}\text { Quantitative: No } \\
\text { Academic Outcome }\end{array}$} \\
\hline & & $\mathrm{No}$ & Yes & $\mathrm{No}$ & Yes \\
\hline Place- & No & $33(21.6 \%)$ & $18(11.8 \%)$ & $55(35.9 \%)$ & $0(0.0 \%)$ \\
\hline Conscious & Yes & $3(2.0 \%)$ & $3(2.0 \%)$ & $39(25.5 \%)$ & $2(1.3 \%)$ \\
\hline
\end{tabular}

\section{Disciplinary Affiliation}

Our second question asked whether these research orientations varied with respect to discipline. The disciplinary affiliation of the first author was indicated on 120 articles. Authors with appointments in colleges of education were coded as Rural Educators, authors with academic appointments outside of a college of education were labeled Rural Social Scientists and authors with nonacademic affiliations were coded as Independent Scholars. Articles for which the discipline of the first author could not be determined were excluded from this portion of the analysis. Of the 120 authors, 70 (45.8\%) were Rural Educators, 34 (28.3\%) were Rural Social Scientists and $16(13.3 \%)$ were independent scholars.
Figure 1 shows the percentage of articles within a given dimension written by authors from each discipline. Rural Educators were underrepresented in the academic outcome dimension and overrepresented in the placeconsciousness dimension; while Rural Educators wrote $45.8 \%$ of all articles they accounted for $34.8 \%$ of the articles examining academic outcomes and $59.0 \%$ of articles accounting for spatial context. Rural Social Scientists, comprising more than one quarter $(28.3 \%)$ of all authors, produced $44.0 \%$ of all quantitative publications and $43.5 \%$ of all papers with an academic focus. Authoring just $13.3 \%$ of all articles, Independent Scholars were overrepresented in the academic outcome $(21.7 \%)$ and place-conscious $(17.9 \%)$ dimensions. In 
general, it appears that most of the place-conscious research in rural education was informed by scholars situated within colleges of education. Furthermore, a significant proportion of the scholarship addressing academic outcomes was informed by scholars with appointments outside of colleges of education. Figure 2 displays the degree to which a discipline collectively incorporates a given research orientation in its work. Of all the articles written by rural educators, approximately one-third (32.9\%) were quantitative, one- tenth $(11.4 \%)$ focused on an academic outcome, and onethird $(32.9 \%)$ were place-conscious. Most (64.7\%) of the articles written by Rural Social Scientists were quantitative, $29.4 \%$ examined an academic outcome and $26.5 \%$ considered influences of place. Quantitative methods were employed in $31.3 \%$ of the articles written by Independent Scholars, while $31.3 \%$ of publications by independent scholars were academically-oriented and $43.8 \%$ were place-conscious.

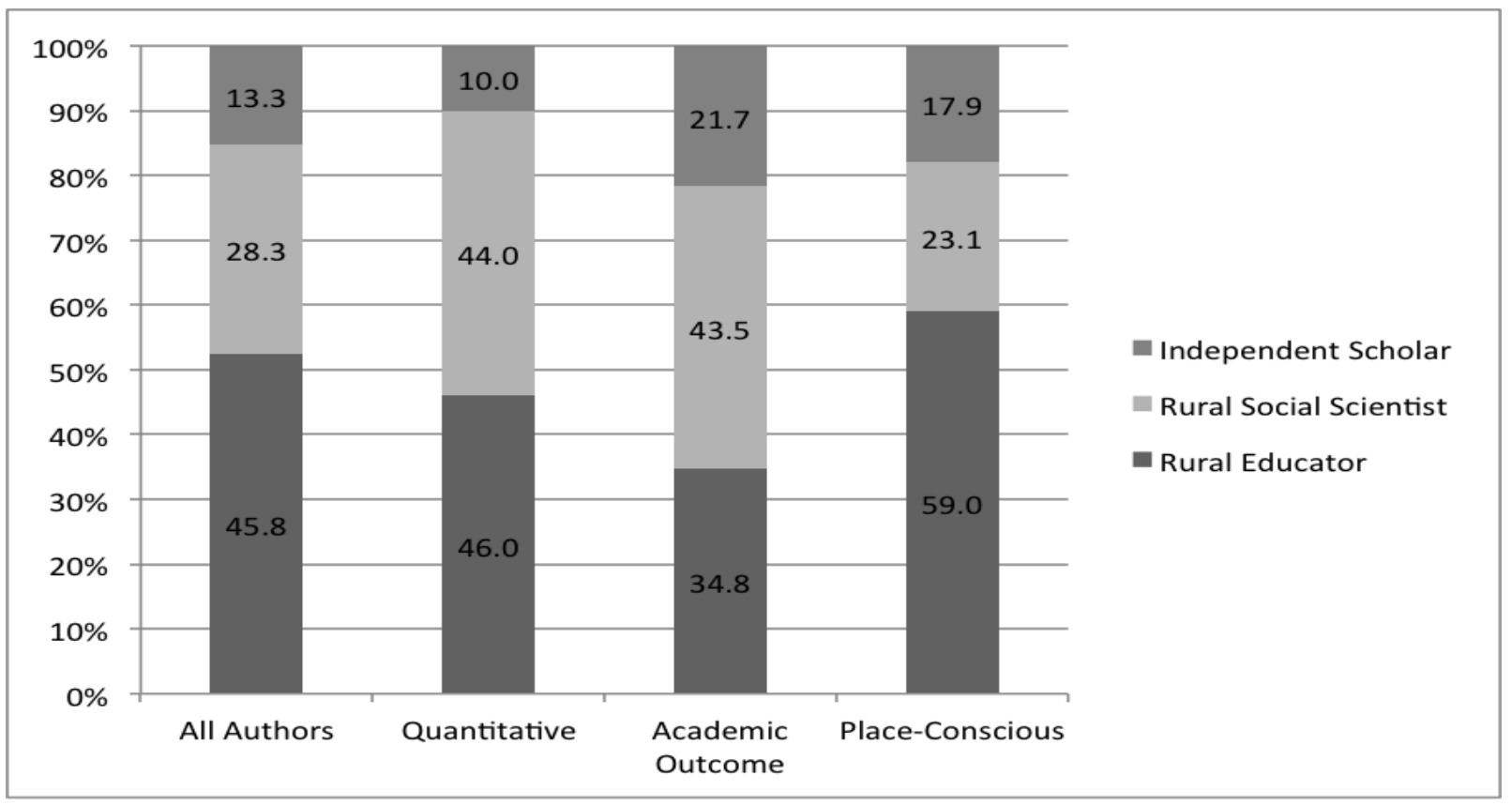

Figure 1. Disciplinary representation among research orientations. 


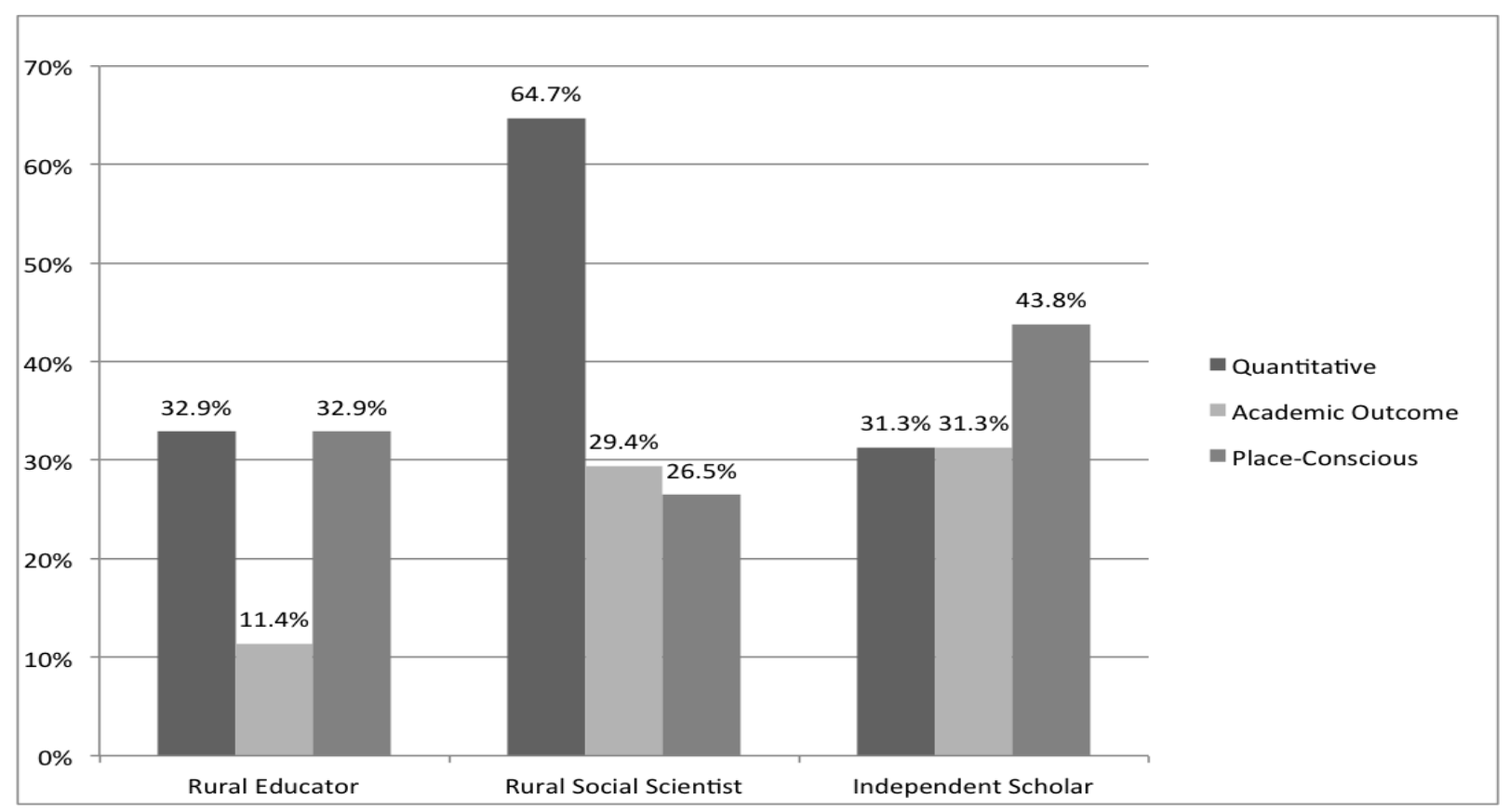

Figure 2. Percentage of articles displaying a given research orientation by disciplinary affiliation.

Articles written by Rural Social Scientists were far more likely to use a quantitative technique than articles written by individuals in other disciplines. Rural Educators were far less likely than their colleagues to identify an academic outcome as their primary dependent variable. Independent scholars were more likely to publish placeconscious research than both Rural Educators and Rural Social Scientists. In sum, these data suggest that most of the Rural Social Scientists who conduct education research do so using quantitative techniques and that most education scholars who conduct rural research choose to investigate non-academic outcomes.

\section{Limitations}

Of course, these analyses were limited by a nonrandom sample of rural education research and a subjective coding scheme. Rural education manuscripts may find their way to JRRE and $R S$ because the research orientations employed in them mirror those of earlier $J R R E$ and $R S$ articles; manuscripts employing other orientations may be submitted elsewhere. Rural Educators overwhelmingly authored our census of JRRE articles, potentially biasing our disciplinary comparisons. Publications like The Rural Educator, Journal of Rural Studies and "mainstream" education and social science journals may attract rural education manuscripts that take a markedly different form. Rural education research from public health, economics, family and consumer sciences, agriculture education and related perspectives was virtually absent from our analyses, but may be present in other publications. A more comprehensive sample of the whole of rural education research must be scrutinized in order for these findings to be generalized beyond the boundaries of JRRE and $R S$.

Additionally, our imperfect and subjective measures were also a limitation. For the sake of simplicity, we did not distinguish between mixed-methods studies, ethnographies, content analyses, literature reviews and other non-quantitative articles. Likewise, we relied on arbitrary, undifferentiated constructions of variables and disciplines in our analyses. Our use of abstracts as the unit of analyses posed (infrequent) challenges to identifying academic outcome variables and degrees of place-consciousness.

\section{Discussion}

Our findings suggest that there are methodological and disciplinary cleavages in the rural education research literature, although the discrepancies ran counter to our initial expectations. While we hypothesized that institutional contexts and education policies would encourage Rural Educators to concentrate on academic outcomes, this was not the case. Rural Educators rarely took up questions of academic performance and appeared to have relatively little influence over this aspect of the rural education literature. We expected that Rural Social 
Scientists would be most likely to contextualize their work, but again our hypothesis proved false as they were underrepresented among place-conscious articles and accounted for spatial context in only one-quarter $(26.5 \%)$ of their publications.

Collectively, these findings imply that while Rural Educators routinely take up place-conscious research that reflects the nuances associated with the administration of centralized policies in rural communities, they do so using methodological tools that likely have the least potential for informing policy. Conversely, the outcomes-oriented research of Rural Social Scientists may display the sort of "rigor" demanded by state departments of education and federal Race to the Top reviewers, but likely fall short of addressing the unique place-based challenges arising when high-stakes, standards-based reforms are implemented in small, rural schools.

The frustrations expressed by rural education advocates (Strange, 2009) about the Obama administration's data-driven expectations for rural schools might be a symptom of a larger problem that very little rural research is both place conscious and outcomesoriented. Our analyses show that rural scholars most adept at meeting data-driven policy requirements do so largely irrespective of rurality while the most placeconscious scholars use research methods with little currency in the current political climate. One must speculate that without engaging in transdisciplinary collaboration neither of these constituencies will prove effective at leveraging state and federal resources, funds or attention. Our recommendations for achieving effective transdisciplinary scholarship are outlined below.

\section{Implications}

We have illustrated the shared commitment to transdisciplinary collaboration on the part of Rural Educators and Rural Social Scientists who study rural education. We have also discussed the necessity of such a project for informing place-conscious policies. Our findings suggest that while both communities are committed to sustaining rural schools and communities, they approach the task using very different tools in terms of methodology, measurement of academic outcomes and attention to place. Despite the challenges inherent in their divergence, we believe their complementary strengths encourage a transdisciplinary research strategy. In light of these revelations we endorse the following strategies for moving toward a sustainable transdisciplinary partnership.

1. Hire creatively. A number of scholars of rural education hold cross-discipline courtesy appointments, primary appointments in interdisciplinary departments and even joint appointments in closely related disciplines. Anecdotal evidence suggests these arrangements largely fail to nurture collaboration that transcends institutional and disciplinary boundaries. Very few scholars hold appointments in both colleges of agriculture and colleges of education. One powerful way to encourage transdisciplinary scholarship is to establish funding priorities and personnel policies that incentivize out-of-discipline and cross-college hires. Education foundations and policy departments should commit to hiring Rural Social Scientists while colleges of agriculture should invest in education researchers. Deans of colleges of education and agriculture should prioritize cross-college job sharing and cluster hiring. Furthermore, bureaucratic impediments that make it difficult for faculty to hold dual appointments across colleges must be removed.

2. Engage stakeholders. These disciplines must work together to radically engage practitioners and other rural education stakeholders. As it stands, academics fail "to attract and engage a broader audience of social scientists, practitioners, policy analysts, and others" (Beaulieu, 2005, p. 8). Practitioners, policymakers, families and communities could be strong and persuasive allies in advocating for increased rural education $R \& D$ support if stronger linkages existed between them and the academy. But in order for university-community partnerships to be sustainable, the relationships between university actors must be strong.

Existing outreach strategies, like developing professional development courses and extension curricula, fall short of the bold partnerships that must be taken. Colleges of education should establish full-time outreach professorships that resemble the cooperative extension model of land-grant colleges of agriculture. These applied researchers would partner with schools, districts, non-profit organizations and extension offices to disseminate current rural education research.

Similarly, Rural Social Scientists should expand school-based partnerships, like existing school-based 4$\mathrm{H}$ clubs, to include in-service teacher training and district leader mentorships. Community development specialists and agents should incorporate school-familycommunity engagement into their purview.

3. Pursue funding. Both constituencies must place an "increased emphasis on interdisciplinary and even transdisciplinary learning and research...in the funding priorities of major research foundations and agencies" (Krannich, 2008, p. 16). By collaborating on major grants, Rural Educators and Rural Social Scientists will move toward transdisciplinary scholarship. 
An example of a grant that encourages this sort of scholarship is the USDA AFRI Rural Development program that requires integrated proposals incorporating either an outreach or education component. One of the AFRI priorities is to "enhance understanding of and develop innovative strategies to build the rural workforce for the present and for the future, including projects to attract and retain rural youth" (USDA, 2009, p. 107) and "interdisciplinary applications focused on the creation of sustainable rural communities by protecting the environment, reducing poverty, and enhancing community economic vitality are strongly encouraged" (p. 108).

Susan Sheridan, Principal Investigator of the National Center for Research on Rural Education, and Thomas Farmer of the National Research Center on Rural Education Support have demonstrated that USDOE Institute of Education Sciences funds are also available to interdisciplinary teams of rural education scholars. The interdisciplinary efforts by National Science Foundation-funded teams at the (albeit short-lived) Appalachian Collaborative Center for Learning, Assessment and Instruction in Mathematics, and the Appalachian Math and Science Partnership should also prove encouraging.

4. Develop existing partnerships. While some scholars have published in both JRRE and $R S$ (e.g., Schafft) most authors have published for a single rural education audience. By publishing outside of our "home" disciplines we can initiate transdisciplinary conversations with colleagues we may not otherwise reach.

Rural Social Scientists who study education have as much, if not more, in common with Rural Educators as they do with the scholars of food and agriculture within their own disciplines. As such the Education and Work Interest Group of the RSS could "become more proactive in attracting rural scholars in allied social science fields" (Krannich, 2008, p. 17) by expanding conference participation to include colleagues from colleges of education and by organizing pre-conference symposia. Similarly, Rural Educators must ensure that groups like the Rural Education Special Interest Group of the American Educational Research Association and the Rural Education Working Group of the Rural School and Community Trust are inclusive of Rural Social Scientists with appointments in colleges of agriculture.

In this paper we have identified complementary strengths and conflicting approaches of Rural Educators and Rural Social Scientists who engage in education research. By examining the influences of Rural Educators and Rural Social Scientists on rural education scholarship we have extended a long series of comprehensive reviews of the rural education literature. While many of the observations found in earlier reviews reappear here, we are hopeful that the trandisciplinary strategies we have outlined will commence a new season of rigorous, placeconscious, policy-relevant research.

\section{References}

Arnold, M. L. (2005). Jump the shark: A rejoinder to Howley, Theobald, and Howley. Journal of Research in Rural Education, 20(20), 1-2.

Arnold, M. L., Newman, J. H., Gaddy, B. B., \& Dean, C. B. (2005). A look at the condition of rural education research: Setting a direction for future research. Journal of Research in Rural Education, 20(6), 1-25.

Beaulieu, L. J. (2005). Breaking walls, building bridges: Expanding the presence and relevance of rural sociology. Rural Sociology, 70(1), 1-27.

Burawoy, M. (2004). To advance, sociology must not retreat. Chronicle of Higher Education, 50(49), B24.

Cicchinelli, L. F., \& Dean, C. B. (2005). It's all about quality of advice, guidance, and research for rural educators: A rejoinder to Howley, Theobald, and Howley. Journal of Research in Rural Education, 20(19), 1-2.
Coladarci, T. (2007). Improving the yield of rural education research: An editor's swan song. Journal of Research in Rural Education, 22(3), 1-9.

DeYoung, A. J. (1987). The status of American rural education research: An integrated review and commentary. Review of Educational Research, 57(2), 123-148.

Farmer, G. (1838). Agriculture. Journal of Education, l(1), 3 .

Holt, J. B. (1936). Current bulletins. Rural Sociology, 1(1), 94-102.

Howley, C. B., Theobald, P., \& Howley, A. (2005). What rural education research is of most worth? A reply to Arnold, Newman, Gaddy, and Dean. Journal of Research in Rural Education, 20(18), 1-6.

Kannapel, P. J., \& DeYoung, A. J. (1999). The rural school problem in 1999: A review and critique of the 
literature. Journal of Research in Rural Education, 15(2), 67-79.

Khattri, N., Riley, K. W., \& Kane, M. B. (1997). Students at risk in poor, rural areas: A review of the research. Journal of Research in Rural Education, 13(2), 79100.

Krannich, R. S. (2008). Rural sociology at the crossroads. Rural Sociology, 73(1), 1-21.

Theobald, P. (1991). Historical scholarship in nineteenth century rural education. In A. J. DeYoung (Ed.), Rural education: Issues and practice (pp. 3-25). NewYork: Garland.

Sanders, I. (1958). Theories of community development. Rural Sociology, 23(1), 1-12.

Sherwood, T. (2000). Where has all the 'rural' gone? Rural education research and current federal reform.
Journal of Research in Rural Education, 16(3), 159167.

Strange, M. (2009, September). Race to where? Rural Policy Matters. Retrieved from http://www.ruraledu.org/articles.php?id=2298

United States Department of Agriculture [USDA]. (2009). Agriculture and Food Research Initiative Competitive Grants Program. Retrieved August 15, 2009 from http://www.csrees.usda.gov/fo/ruraldevelopmentnri.c fm.

United States Department of Education [USDOE]. (2001). No child left behind: A desktop reference. Retrieved May 10, 2008 from http://www.ed.gov

United States Department of Education [USDOE]. (2009). Race to the Top Fund. Retrieved March 1, 2010 from http://www.ed.gov

\section{About the Authors:}

Chris Stapel is a PhD candidate in sociology at the University of Kentucky. His research is at the intersection of sociology of education, rural sociology, and sociology of sexualities.

Alan J. DeYoung is Professor and Chair of the Department of Educational Policy Studies and Evaluation at the University of Kentucky. His research has focused upon the history and sociology of education in Appalachia, and more recently upon rural schools, rural education, and "problems of education transition" in the Central Asian republics of the former USSR, primarily Tajikistan and the Kyrgyz Republic. 